\title{
10
}

\section{A PRAGMATIC APPROACH TO DEFINING SEX/GENDER}

Ask yourself how you would define the category "human." Aristotle was the first in Western philosophy for whom there is extensive evidence documenting efforts to answer such a question and, like many who followed, he focused on how to distinguish humans from other animals based on our linguistic and rational faculties. In Joanna Bourke's important historical survey, she describes many efforts to define what it means to be human, noting at the outset that "It turns out that the concept 'human' is very volatile. In every period of history and every culture, commonsensical constructions of 'the human' and 'the animal' exist, but the distinction is constantly undermined and re-constructed" (2011, 13). Reaching a consensus on how to define "human" is quite difficult: "conventional distinctions between human and nonhuman animals are applied inconsistently, or are simply wrong. Is intellectual ability the crucial criterion? Or self-consciousness? Or the possession of a soul? Or toolmaking? Or private property? Or genetic inheritance?" (15).

In Defining Reality, I argue that new definitions should be thought of as prescriptive and theory-bound $(2003,49-68)$. That is, a new definition is a proposal for how we ought to use a term in the future. And definitions depend on a set of beliefs about the world that can be described as a theory. Paul T. Sagal suggests that asking "what is $[\mathrm{x}]$ questions" is tantamount to asking for a "rigorous, consistent, complete theory" that would include "an implicit definition of x" (1973, 446-447). For those reasons, efforts to define "human" are competing theories that are informed by specific beliefs about the world, including biological, psychological, economic, political, legal, and religious beliefs. The beliefs considered most important or valuable to a thinker will be the ones that influence which traits of human beings are deemed most "essential" or definitive. As needs, interests, and values change over time, so do theories of what is human. And those theories have proven to have important implications for answering such crucial questions as: Are women persons? Are the enslaved human? Do animals have rights? (Bourke 2011). 
Given how difficult it is to define "human," it should come as no surprise that it is equally challenging to define "woman" and "man." That is, if it seems impossible or at least implausible to determine a "final" definition of "human" that meets all potential stakeholders' needs and interests, then it seems straightforward to accept Rebecca Solnit's claim that "There is no one-size-fits-all definition of what a woman [or man] is" (2020). On one hand, a too-narrowly tailored biological definition erases transgender, nonbinary, gender-fluid, and DSD people and perpetuates biological essentialism — a key source of sexist prejudice throughout much of history. On the other hand, pure autonomous nominalism-gender-fluid self-identification unfettered by time or place-denies the possibility of legitimate concerns in specific sex-segregated contexts, as described in Part II of this book. Once we set aside the need for a one-size-fits-all set of definitions, then we are able to look at issues such as who should have the power to define, whose interests are being served, and above all the purpose a given definition is serving in a specific context.

In my earlier book on definitions, I argued that when we are faced with a definitional rupture the "What is X?" question needs to be replaced with questions such as, "How ought we use the word X given our needs and interests?" "What is the purpose of defining X?," and "What should count as X in context C?" I advocated a pragmatic approach that sees definitions as made not found, and treats the definitional process as one involving important ethical questions of values, interests, and power. This book has been an effort to apply such an approach to competing definitions of sex and gender emerging in the 21st century amid what I have described as the Transgender Exigency.

\section{Defining with purpose}

The first theme of this conclusion is that we need to define with purpose. The purpose in defining sex/gender can vary significantly in different contexts. When I asked college-aged Anastazy, who identifies as a nonbinary transgender man, how they fill out paperwork that asks about gender, they replied that it depended on the context:

If it's for something that isn't medical related, I put male. For medical stuff I put female since it's what my body is, and it makes sure that I can get the most care I need. If things were my way, there would be a section where you could fill in the blank. That way it is easier for each person to explain their gender, and it takes some of the stigma away of being trans.

(Anastazy 2020)

The challenge of defining sex/gender for transgender patients in medical contexts is underscored by a tragic case recounted in the New England Journal of Medicine when a transgender man was admitted into the emergency department with lower abdominal pain (Stroumsa et al. 2019). "Sam" (a pseudonym) 
had not transitioned surgically, though he had previously been taking testosterone and presented as a man. Sam was, in fact, pregnant. He had had a positive result with a home pregnancy test that morning, and despite the fact that the triage nurse ordered a pregnancy test (a serum hCG test), she "did not incorporate that possibility [of pregnancy] into the differential diagnosis in a way that would affect ensuing classifications and triage decision making"; as a result, he was not treated with the urgency that his and the baby's health required. A team of doctors analyzing the case after the fact concluded that "the triage nurse did not fully absorb the fact that he did not fit clearly into a binary classification system with mutually exclusive male and female categories": A cisgender woman with the same symptoms would have been "directed to urgent obstetric evaluation" (Stroumsa et al. 2019). Sam was not treated immediately and lost the baby due to undiagnosed umbilical cord prolapse. Doctors concluded that "earlier evaluation might have resulted in detection of the cord prolapse in time to prevent fetal death" (Stroumsa et al. 2019).

The challenge is not solely a matter of definition, but also to advance supportive and understanding attitudes and behaviors toward transgender people in all contexts, especially when it relates to issues of health and safety. A more flexible and pragmatic approach to understanding sex/gender would encourage us to think about our identities as multifaceted, such that no tension is felt between saying I am a man and (not "but") medically you need to check me for pregnancy.

Such flexibility is not easy to put into practice. Aside from proper names, language cannot function without categories. For those categories to "work," they have to be shared and there has to be some level of what I have described as "denotative conformity." Categories succeed by excluding; that is, one's understanding of X typically requires one to understand what is not-X. Much early language acquisition depends on learning prototypical exemplars of what "counts" as an X, and being corrected by more experienced language users when we "overextend" a category — by counting an orange as a ball, say_ or "underextend" a category — by not counting a football or wiffle ball as a ball (Schiappa 2003, 11-29).

However, once a category gains wide acceptance, people adopt the "natural attitude" toward it; that is, we take the category as "given" (rather than socially constructed) and that is when all sorts of problems can emerge, including essentialism, reductionism, and-in the case of categories of people-stereotypes and prejudice. Think of this cycle as the category paradox. That is, we benefit from categories as necessary tools to make sense of reality, but the same cognitive functions that make shared categories socially useful (learning to recognize attributes of category $\mathrm{X}$ and to exclude not-X attributes) often carry the price of forgetting that categories are made not found, revisable and contingent social constructions rather than fixed realities. Ron Mallon calls this "the reification problem": the "mistaken belief in the naturalness of a category can be one of the mechanisms by which the category is sustained" $(2016,216)$.

In the past 50 years, there has been growing recognition that the categories of "woman" and "man" are socially constructed, but what do we do with that recognition? Ian Hacking in his useful book The Social Construction of What? describes 
six gradations of social constructionist commitment: Historical, Ironic, Reformist, Unmasking, Rebellious, and Revolutionary. These gradations begin with the modest acknowledgment that a particular category $\mathrm{X}$ is a product of history: "Someone presents a history of $X$ and argues that $X$ has been constructed in the course of social processes. Far from being inevitable, $X$ is the contingent upshot of historical events" $(1999,19)$. At the other end of the spectrum are activists: "An activist who moves beyond the world of ideas and tries to change the world in respect of $X$ is revolutionary" (1999, 20). Hacking correctly observes that with respect to "gender," one finds the whole range of responses evident:

As our consciousness about gender is raised, some of us find our attitudes moving along from historical to ironic to reformist, and then to unmasking the function of gender relations. With the mask removed, we become rebellious; a few become revolutionary.

$(1999,20-21)$

The ongoing social and political conflicts surrounding transgender issues suggest that, as a society, we are far from all being on the same page as far as how much of the world we are willing to change when it comes to sex/gender. At a minimum, I argue it is crucial that we collectively gather at the ironist/reformist stage. Hacking acknowledges that his label "irony" is informed by Richard Rorty's description in Contingency, Irony, and Solidarity (1989). Hacking notes: "Irony about $X$ is the recognition that $X$ is highly contingent, the product of social history and forces, and yet something we cannot, in our present lives, avoid treating as part of the universe in which we interact with other people, the material world, and ourselves" (1999, 20). Having acknowledged the historicity of sex/gender categories, we can do our best to improve those categories — a stance described by Hacking as Reformist: We may

have no idea at present how to live our lives without $X$, but having seen that $X$ was not inevitable, in the present state of things, we can at least modify some aspects of $X$, in order to make $X$ less of a bad thing. This is reformist constructionism.

$(1999,20)$

For example, a strong reformist element can be seen in recent decades in the scholarship concerning the category of masculinity. We have come a long way from treating masculinity as an essential part of being a man. Instead, today masculinity is more likely to be seen as a historically and culturally contingent set of beliefs, attitudes, and behaviors, or even an ideology. Indeed, since 2000, an academic journal has been dedicated entirely to the Psychology of Men \& Masculinity. Scholars have moved from treating masculinity as unidimensional to multi-dimensional (see Chapter 2), with a variety of measures of masculine norms in use. Moreover, important work by psychologists has investigated the harms of certain forms of 
masculine role socialization, generally studied under the rubric of Gender Role Conflict (GRC). ${ }^{6}$ As of 2015, there have been 350 studies of GRC (O'Neil 2015, 4). Masculine norms are changing in the United States, a fact that underscores the historical and cultural contingency of gender norms: "More than ever before, men are being allowed to be vulnerable, emotional human beings. This transition is hopeful and important, but painfully slow" (O’Neil 2015, 10).

Attitudes and beliefs about gender can now be thought of as ideology - that is, a set of culturally specific political beliefs. "Traditional Masculinity Ideology" (TMI) describes masculine norms that harken back to the time before the questioning of gender roles in the 1970s, including toughness, avoidance of femininity, negativity toward sexual minorities, dominance, and restrictive emotionality. TMI is rooted in "patriarchal, Western, heteronormative, and traditional perspectives of men" (Levant \& Richmond 2016). Of course, one does not need to be born and raised male to embrace Traditional Masculinity Ideology, or to act on such ideology. ${ }^{7}$

To summarize the argument thus far: We are past the point where it is possible to stipulate a one-size-fits-all definition for male/female or woman/man. There is simply no good alternative to recognizing that sex/gender categories must be treated pragmatically. That is, in specific contexts we need to decide whether sex/ gender is even necessary to reference. When there are good reasons to do so, we need to define with purpose. Just as our contexts vary (for example, from a dating site to a doctor's office), so too will the purpose of defining.

As I noted at the beginning of this book, I believe that self-identification, or first-person authority, should be presumptive. "Presumptive" does not mean absolute and unfettered, however. As feminist philosopher Naomi Scheman, cited in the last chapter notes:

while it may often be just fine for me-as it ought to be just fine for a trans woman-to identify simply as a woman, it's not solely up to me to determine when and why it might not be just fine: judgments of importance or appropriateness are not solely mine to make

(2018, 188)

So how do we make decisions about which contexts require something more-in particular, a regulatory definition? That is the question pursued in the next section.

\section{When might self-identification not be enough? The imperfect analogy with race}

Before I turn specifically to the issue of regulatory definitions impacting transgender people, I want to discuss another definitional challenge that may serve as a useful though imperfect analogy. ${ }^{8}$ In particular, I want to consider what has been described as transracialism, hereafter referred to as trans-r. ${ }^{9}$ Trans-r people claim a racial identity for themselves that differs from what can be called their "birth race." The most infamous recent example is Rachel Dolezal, a woman of white ancestry 
and who identified as black and "passed" as black, at one point leading the Spokane, Washington, branch of the NAACP before she was "outed" as white in 2015.

Dolezal is not the only self-identified trans-r person in recent history. German model/actress Martina Adam (or "Martina Big"), who now goes by the name Malaika Kubwa, was born white but underwent dermatological treatment to darken her skin and now claims an African identity (Big 2020). Jessica A. Krug was a professor of history and Africana Studies at George Washington University who revealed on September 3, 2020 that she was born to white parents but had been passing as a black woman throughout her professional life (Lumpkin \& Svrluga 2020). I shall return to Krug's case below, but since her revelation, at least one other white person has confessed to similar efforts to pass as non-white (Vee 2020).

In 2017, prompted by sympathetic media coverage of Caitlyn Jenner and negative coverage of Rachel Dolezal, philosopher Rebecca Tuvel published "In Defense of Transracialism," in which she suggests that "similar arguments that support transgenderism support transracialism" (2017, 275n). Tuvel's essay was not the first philosophical paper to explore such a thesis (see Heyes 2006; Overall 2004), but the publication of her essay in the leading journal of feminist philosophy ignited an academic firestorm. It is not necessary for the purposes of this project to review (let alone resolve) the various issues of contention involved. ${ }^{10}$ The threads from the academic discussion of Dolezal's case that I want to draw attention to are those that reflect the need to triangulate among three issues: Who has the right to define, the purpose of defining, and specific contexts.

Prior to Tuvel's intervention, a group of philosophers informally tackled the question of how to react to Dolezal's claim to be black. The conundrum facing philosophers was and remains to reconcile the widely shared belief that "race" is a social construct and a "biological fiction" with the fact that race often has been used as a tool of prejudice and oppression. As columnist Courtland Milloy put it, "Race is a biological fiction, a concept with no basis in anatomy. It is a myth, pseudoscience, a fraud, a social con job" (2018). Nevertheless, racism persists. As philosopher Kwame Anthony Appiah puts it,

Much of the elaborate scientific superstructure that grew up around race was dismantled in the past century. . . . But the world outside the sciences hasn't taken much notice. Too many of us remain captive to a perilous cartography of color.

$(2018, x v)^{11}$

Thus, Dozenal's case compels theorists to specify how race can be invoked, by whom, and to what purpose. Philosopher Esa Díaz-León acknowledges that race is a social construction, but suggests that two important definitional attributessocial position within a social hierarchy, and shared historical properties - serve "crucial" explanatory roles, "such as explaining a history of racial discrimination and revealing different social structures of oppression." Based on those two sets of attributes, Díaz-León concludes that "it's not clear at the moment that a concept 
of race based (solely) on self-identification is politically useful to a similar extent" (in Weinberg 2015). In a similar vein, Meena Krishnamurthy suggests that the key definitive attribute should be ancestry, which again would challenge the ability to self-identify one's race:

Ancestry is the appropriate basis for referring to people as "black" because it tracks politically relevant considerations such as oppression and slavery (historical political injustices), which are considerations that ought to be given weight to and taken into consideration when we interact with others in the public sphere. This is what self-respect and a just society require.

(in Weinberg 2015)

Note that these philosophers are not making a metaphysical argument about what race "really is," but rather are identifying attributes that they consider "essential" for the pragmatic purposes of social justice. Such an approach resonates with William James's claim (quoted earlier) that "The essence of a thing is that one of its properties which is so important for my interests that in comparison with it I may neglect the rest" $(1981,961)$. Thus, for the purposes of defining race with an eye toward recognizing the historical injustices associated with racism, historical practices and status (including enslavement) are vitally important, and thus should take priority over claims of self-identification. ${ }^{12}$

Similarly, analytic philosopher Quayshawn Spencer notes that the category of race has practical implications in various institutional policies and regulations, and thus a shared definition of race and honesty about ancestry advances goals of social justice:

So, why does any of this matter? Well, one reason is because linguistic competence and honesty about one's racial membership(s) is presupposed in the execution of many social programs designed to promote social justice. For instance, the preferential treatment of Blacks in college admissions and faculty hiring, the federally-mandated racial tracking of mortgage loan borrowers, the [FBI's] racial tracking of hate crimes, and the Department of Health and Human Services' racial tracking of health disparities all rely on Americans being linguistically competent and honest about their racial membership(s) in census racial discourse.

(Spencer, in Weinberg 2015) ${ }^{13}$

Thus, the situation with race and self-identification, as these philosophers see it, is not unlike the approach described in this book with respect to sex/gender. Yes, in most contexts, people can and should be able to identify themselves as they wish. Once that identity is declared in practical or institutional contexts that involve the cooperation of others, however, we are dealing with a social identity that requires social recognition, sometimes negotiation, and if the stakes are high, definitional regulation. In the cases where white academics passing as non-white 
were discovered, the individuals were criticized because they had received material resources to support their work that could have otherwise gone to Black or Latino scholars. In Jessica Krug's case, she lost a tenured faculty position at George Washington University after she was revealed as white and it was learned that she had misrepresented her upbringing as stereotypically non-white and impoverished, such as falsely claiming her parents were addicts and her mother was a sex worker (Wamsley 2020).

On March 22, 2021, the city of Evanston, Illinois, approved a program for local reparations for Black residents, initially focusing on housing. The program "acknowledges the harm caused to Black/African-American Evanston residents due to discriminatory housing policies and practices and inaction on the City's part," and offers financial compensation. Consistent with what the philosophers cited earlier advocate, the program's definitions focus on ancestry, and define "Black or African-American" as "A person having origins in any of Africa's black racial and ethnic groups" (City of Evanston 2021). Similarly, William A. Darity, Jr. and A. Kirsten Mullen, authors of From Here to Equality: Reparations for Black Americans in the Twenty-First Century (2020), argue that two conditions are "critical" for determining eligibility for reparations: "[R]ecipients must have at least one ancestor who was enslaved in the United States"-a requirement consistent with other definitional approaches—and, interestingly, "recipients also must show that they self-identified as Black, Negro or an equivalent designation on an official document for at least 12 years before a reparations program was set in motion" (Mullen \& Darity 2021).

\section{When might regulatory definitions be desirable?}

Returning to the issue of definition with respect to gender, what might be gleaned from the previous discussion of self-identification and race? Put most simply, there need to be compelling reasons to impose a regulatory definition. Activist-scholar Heath Fogg Davis argues in his book, Beyond Trans: Does Gender Matter?, that "all of us would be better off in a society with dramatically fewer sex-classification policies" $(2017,17)$. I agree with the thesis that we do not need regulatory definitions for sex/gender unless a legitimate purpose is being advanced in specific contexts. Davis describes in an appendix and a companion Workbook how to perform a "gender audit exercise" that is intended to encourage gender-inclusive design strategies $(2017,151-157,2018 a) .{ }^{14}$ For example, the dominant practice of sex-segregated restrooms has the stated purpose of ensuring privacy and safety, but properly designed all-gender restrooms could advance such purposes without discriminating based on sex/gender and avoiding the consequences of people being "policed" based on their appearances and gender-based assumptions.

I wish to take Davis's idea of a gender audit a step further to think about a framework for thinking about how and when regulatory definitions of sex/gender are appropriate. Such an approach is consistent with that taken in the UK, where the Equality Act of 2010 permits actions involving sex segregation, including with 
respect to gender reassignment if such acts are "a proportionate means of achieving a legitimate aim" (2010, 150). This notion of proportionate means achieving legitimate aims is pursued in the next section operationalized as "levels of scrutiny."

The United States does not have an Equality Act akin to the UK's Equality Act of 2010, though one has passed in the U.S. House of Representatives (H.R.5 Equality Act). H.R.5 is an act "To prohibit discrimination on the basis of sex, gender identity, and sexual orientation." The bill defines gender identity as follows: Sec. 1101(a) “(2) GENDER IDENTITY.-The term 'gender identity' means the gender-related identity, appearance, mannerisms, or other gender-related characteristics of an individual, regardless of the individual's designated sex at birth." The bill as currently drafted has been criticized in part because of the obvious circularity of the definition of gender identity — “ ' gender identity' means the gender-related identity" - and the absence of any sort of framework or regulatory definitions for adjudicating claims for contexts in which sex/gender based segregation may be relevant (as explored in Part II of this book). ${ }^{15}$ In its current form, the Equality Act is unlikely to be approved by the U.S. Senate (AP 2021b; Burns 2021). It is likely that passage will require some sort of pragmatic framework or wording similar to the UK's Equality Act (allowing sex segregation if such acts are "a proportionate means of achieving a legitimate aim”).

It may be recalled from the previous chapters that a number of regulatory definitions for sex/gender have been used or proposed. The simplest way to describe self-identification as a regulatory definition would be: Anyone who self-identifies at the moment as a woman/man $(\mathrm{X})$ counts as a woman/man $(\mathrm{Y})$ in this context $(\mathrm{C})$. Note that there is no temporal requirement of duration stipulated. Most contexts that still prefer sex segregation (for specific contextual reasons) add the requirement of duration, either past or future, such as some of the single-sex schools discussed in Chapter 4: Anyone who consistently lives and identifies as a man/woman (X) counts as a man/woman (Y) in the context of applying to this institution (C). "Lives as" is somewhat open-ended, but in the context of a single-sex school, one's future intentions are salient, and presumably one must transition socially, including using gender-specific pronouns and names.

Some contexts, such as bathrooms in states without the so-called bathroom bills, function with an implicit regulatory definition: People perceived as a male/female (X) counts as a man/woman (Y) in the context of public bathrooms and changing facilities (C). In many non-institutional settings, the only social "requirement" is that one passes. While there may not be "official" sanctions for not-passing, there is a threat of violence that all too many transgender people must contend with. Note that with the single-sex school example, the student has the presumptive power to define herself or himself. As we move to more restrictive regulatory definitions, that power shifts as decisions are a negotiated outcome with others.

Some regulatory definitions attempt to recognize transgender individuals but require more than self-identification, such as the military's requirement for an "official" diagnosis of gender dysphoria. Some institutions defer the authority to define to "official" (i.e., medical or governmental) agencies, such as Anyone who is 
legally recognized as a woman/man (X) counts as a woman/man (Y) in this context (C). Such approaches sometime stipulate the birth certificate as the controlling official document, which is why the ability to amend one's birth certificate is so important to transgender people.

Some regulatory definitions require one either to be receiving hormone therapy and/or undergo surgical reassignment to pass the requirements of a specific definition, such as in elite sports, prisons, or to obtain legal identification in some jurisdictions. Some biology-based regulatory definitions, including that previously advanced by the Trump administration, are intended to ignore the possibility of transgender and DSD people, such as Only those assigned the sex female/male at birth $(\mathrm{X})$ counts as women/men $(\mathrm{Y})$ in this context, or Only those with male/ female chromosomes count as male/female $(\mathrm{Y})$ in this context.

The point is that regulatory definitions range from easy to extremely difficult to satisfy. The argument I am advancing with different levels of scrutiny is a simple one: The more onerous the regulatory definitional requirements, the stronger the justification must be.

\section{Levels of scrutiny}

I advocate an approach analogous to that found in U.S. constitutional law known as different "levels of scrutiny" applied to laws and regulations that restrict individual freedom. ${ }^{16}$ Deference here is to individual freedom, and it is the institution involved that must meet increasingly higher levels of scrutiny as more restrictive regulatory definitions are proffered. It may be useful here to describe the levels of scrutiny recognized in U.S. constitutional law before explaining how I adapt them as levels of scrutiny specific to the regulatory definitions of sex/gender.

Erwin Chemerinsky, Dean of the University of California, Berkeley, School of Law, notes in his influential textbook on constitutional law that "In a sense, the level of scrutiny provides instructions for balancing. It informs courts as to how to arrange the weights on the constitutional scale in evaluating particular laws" (2015, 789). The lowest level of scrutiny is known as the Rational Basis Test. This test holds that government action is permissible as long as it is "rationally related" to a legitimate government purpose. So, for example, state laws that set a minimum age to obtain a driver's license in fact "discriminate" against those younger than the minimum age, but have been supported by the courts because such laws serve a legitimate purpose of public safety. This level of scrutiny sets a very low bar for government regulation as it is presumed that laws have a rational basis; as a result, it has been invoked very rarely by the Supreme Court to invalidate a law or regulation. ${ }^{17} \mathrm{I}$ include the Rational Basis Test only in the interest of contrasting it to the other two levels of scrutiny, which will be far more relevant to the framework I advocate concerning regulatory definitions of sex/gender.

The next level of scrutiny is known as Intermediate Scrutiny. As Chemerinsky states, "Under intermediate scrutiny, a law will be upheld if it is substantially related 
to an important government purpose" (2015, 790, emphasis in original). The wording may seem only subtly different than what I just described as the Rational Basis Test, but note the substitution of two key words - substantially for rationally, and important for legitimate. The idea is that when Intermediate Scrutiny is applied, the stakes are acknowledged as higher, so the burden of proof is increased on the government and justification must be correspondingly stronger. For example, the First Amendment to the U.S. Constitution states that Congress shall make no law abridging freedom of speech, but over the years a number of government restrictions have been permitted by the Supreme Court, such as regulation of commercial advertising, when the justification is substantially related to an important purpose.

A more relevant set of Intermediate Scrutiny cases are those in which the Supreme Court has reviewed regulations based on sex. It was not until 1971 that the Supreme Court first struck down a classification based on sex (Chemerinsky 2015, 1086). Before that time, laws that prohibited women from becoming attorneys, from voting, or that restricted women's ability to work as bartenders, were upheld with the logic of what we now call the Rational Basis Test. In a series of cases in the 1970s, the Court wrestled with what the appropriate level of scrutiny should be with respect to sex classifications, vacillating between Rational Basis and Strict Scrutiny. Finally, in the 1976 case of Craig v. Boren (429 U.S. 190), the Court described what is now labeled Intermediate Scrutiny when it struck down an Oklahoma law that set different ages at which men and women could purchase alcohol, proclaiming that to survive constitutional challenge, "classifications by gender must serve important governmental objectives and must be substantially related to those objectives" (197, quoted in Chemerinsky 2015, 1092). In the important case of United States v. Virginia (518 U.S. 515 [1996]) the Court declared the exclusion of women by the Virginia Military Institute unconstitutional. Justice Ruth Bader Ginsburg applied Intermediate Scrutiny and declared that parties "who seek to defend gender-based government action must demonstrate an exceedingly persuasive justification for that action. . . The burden of justification is demanding and it rests entirely on the State" (515, quoted in Chemerinsky 2015, 1093).

It should be noted that the Court looks closely at the purpose of sex/gender classifications. Restrictions based on gender role stereotypes are not allowed, but classifications "benefitting women designed to remedy past discrimination and differences in opportunity generally are permitted” (Chemerinsky 2015, 1097).

The final and highest level is Strict Scrutiny, under which "a law will be upheld if it is necessary to achieve a compelling government purpose" (Chemerinsky 2015, 791, emphasis in original). Again, the stakes are raised with the terms necessary and compelling. The government action under scrutiny must be shown to be the only way to achieve a crucial and vital purpose. The first case applying Strict Scrutiny was the 1944 decision of Korematsu v. United States (323 U.S. 214), challenging the constitutionality of segregation and internment of all persons of Japanese ancestry from certain parts of the U.S. The decision was the first to apply Strict Scrutiny to government actions based upon racial classifications. Though the Court ruled that 
the need to protect against espionage (the case took place during World War II) outweighed the rights of Americans of Japanese descent, the application of Strict Scrutiny would become an important legal tool in the future against laws discriminating based on race.

To be clear, I am not trying to map my framework for thinking about levels of scrutiny concerning regulatory definitions of sex/gender exactly onto the levels of scrutiny found in U.S. constitutional law. My hope by describing these levels is to facilitate thought and discussion that promotes greater nuance than an either/or choice of autonomous nominalism and biological essentialism.

Given the values and interests explicated in the chapters in Part II, a brief description of the levels can be described as follows:

Level Zero:

Self-Identification is definitive. No need for documentation as self-declaration is sufficient. No temporal constraints; that is, ephemeral status or nonbinary status always acceptable. Examples: Non-institutional social settings, including bathrooms.

Level One:

There is a rational basis, grounded in history, served by sex segregation in this context. Self-identification is sufficient, but may require commitment to live as a gender not necessarily assigned at birth. Social transition required but not medical transition. Example: Single-sex schools.

Level Two:

Intermediate scrutiny: There is an important value or set of values served by sex segregation in this context that requires a documented condition of gender dysphoria and/or a durational criterion to "count" as a gender other than that assigned at birth. Examples: Interscholastic sports, Military, Prisons.

Level Three:

Strict scrutiny: Sex segregation advances an important interest that can only met through meeting specific durational and medical transitional criteria. Example: Elite Competitive Sports.

My placement of different contexts within specific levels is intended to reflect the current rationale (values and interests) for sex/gender segregation as identified in Part II. They are not necessarily a reflection of my personal preferences, nor are they intended to be definitive. Rather, this account is offered as a heuristic framework to stimulate thinking and discussion about regulatory definitions concerning sex/gender in a manner that acknowledges the proposition that as the institutional context changes, so do the stakes. 


\section{Personal identification}

The various forms of identification we routinely use that carry a designation of sex/gender is an example of implicit regulatory definitions at work. As Heath Fogg Davis notes, "[ $\mathrm{t}]$ he government agencies that issue and administer our sex-marked birth certificates, driver's licenses, and passports never define the terms 'sex' or 'gender',' thus how the terms are defined and applied imply rather than spell out specific definitional criteria $(2017,29)$. Formally defined or not, having a name or sex/gender designation on one's ID that is at odds with one's transgender identity can lead to serious difficulties, thus obtaining a name change on documentsnot only government-issued documents but items like bank accounts, academic record, leases, paychecks, etc.- - is an important step for many transgender people (National Center for Transgender Equality 2016a). Thus, the Department of State's announcement on June 30, 2021 that it plans to permit self-identification of gender on passports is significant and noteworthy (Blinken 2021).

The sheer complexity of the matter - the many different jurisdictions and myriad types of IDs and documents involved-prevent more than cursory treatment here. As noted transgender activist and political theorist Paisley Currah observes, "The state is not a singular entity, defined by structure or function, but an array of agencies, legislatures, and courts relying on practices, laws, and norms that operate-often at cross-purposes — at every level of government" (in Fischel 2019, 89). The result is a variety of different regulations and policies to determine, for example, when an individual may change their designated sex on official records:

$[F]$ or these various apparatuses of governing, sex was malleable, dependent on the particular remit of the agency. Sex was not a property to be classified according to some ideal, but rather something to be defined based on what it accomplished for a particular governing rationality.

(in Fischel 2019, 90)

Davis argues that such designations are not necessary for the purpose of government-issued IDs, and he questions whether there is a legitimate government interest "in collecting and recording sex-identity information about us" $(2017,48)$. The pragmatic approach advocated here suggests that sex-identity information on IDs should be limited to contexts where a legitimate purpose is served. If there is no such legitimate purpose, then self-identification should be presumptive, ceteris paribus. If all else is not equal and there is some pressing reason to impose a regulatory definition, then the levels of scrutiny described here would obtain.

An example of such pragmatic reasoning is a recent Federal District Court decision in Corbitt v. Taylor that struck down policy order 63 of the Department of Public Safety in Alabama that specifies people's genitalia must be used to determine the sex indicated on their driver's license. Only transgender people who can document that they have undergone gender reassignment surgery were allowed to change the sex indicated on their driver's license. This requirement functions as a regulatory 
definition since it defines "sex" based on the physical attribute of genitalia. The requirement imposed substantial burdens on transgender people who could not afford or did not desire such surgery, since it required them to "bear a driver license with a sex designation that does not match the plaintiffs' identity or appearance" (Thompson 2021, 7). The court noted, "carrying licenses with sex designations that do not match plaintiffs' physical appearance exposes them to a serious risk of violence and hostility whenever they show their licenses" (8).

As the framework of levels of scrutiny I have described indicates, the more onerous the definitional criteria, the more compelling the institution's rationale must be. And indeed, requiring surgical reassignment is the most onerous requirement possible. In this case, the court explicitly applied "heightened scrutiny" since sexbased classifications were involved. The court ruled that Alabama's rule failed to meet such a standard, because their "interests are insubstantial or were formulated post hoc, and because the policy is inadequately tailored to advancing them" (10). Such state interests as administrative convenience and consistency between procedures to change birth certificates and driver licenses were considered inadequate.

Another justification offered by the state for policy order 63 was to facilitate identification by law enforcement, specifically for booking and search purposes. The court rejected this rationale for two reasons. First, the reason was offered post hoc, after the fact, and there was no evidence that such a purpose was considered when policy order 63 was first created (34-36). Such post hoc rationalizations are not sufficient to pass heightened levels of scrutiny. Second, no evidence was offered "showing how a license with a sex designation that differs from the license-holder's appearance could help officers confirm that the license matches the driver" (40). Indeed, the court noted that the "record suggests that licenses denoting the licenseholder's genital status are wholly unhelpful for this purpose" (40).

The court's reasoning in Corbitt $v$. Taylor nicely illustrates the pragmatic approach to regulatory definitions advocated in this book. The definitional rule imposed by policy order 63 was "People with male (or female) genitals $(\mathrm{X})$ count as male (or female) (Y) in the context of applying for an Alabama driver's license (C)." Requiring evidence of surgical reassignment to "count" as female or male falls under what I have described as Level Three strict scrutiny, and I see no reason to disagree with the court's assessment that it fails even a lesser, intermediate level of scrutiny. The harms caused by such a requirement outweigh the stated benefits and thus fail on pragmatic grounds. One can take the argument one step further, as Fogg does, to question whether or not state driver licenses need a sex classification marker at all (2017), since other information on the license, including the photo, can serve the pragmatic purposes of identification.

\section{The future of defining sex/gender}

It should be clear by now that the definitions of the words "sex" and "gender," "female" and "male," "man" and woman," are in varying degrees of flux. Obviously, context matters. Most of the time and in most places, people use the words 
"sex" and "gender," "female" and "male," "man" and woman" without confusion or fear of contradiction. Usage of such terms typically displays a high degree of denotative conformity. With increasing frequency, however, what would appear to be a straightforward question can turn into a definitional rupture that requires us to consider the purposes and processes of definition itself: Is this person a man or a woman in this particular context? It depends on how we define the words man and woman, which in turn depends on our purposes and interests. When definitions are deployed by institutions with the power to enforce them, they become regulatory definitions that deserve critical examination as policy proposals. Once we set aside the impossible myth of a "one size fits all" definition, then it is possible to appreciate the importance of considering the specific values and interests advanced by competing definitions in specific contexts. The same can be said about methods of definition. That is, self-identification is one method of determining whether an individual is male, female, or gender nonconformist, requiring the use of chromosome analysis is another. Each approach advances different values and interests that can-and should-be evaluated according to the context in which definition occurs.

"Nothing About Us Without Us" is a phrase that can be traced back centuries. Nihil novi literally means "nothing new" but as early as 1505 was associated with the Polish political doctrine Nihil novi nisi commune consensus - nothing new without common consent (Rzegocki 2019). In vernacular Polish this became Nic o nas bez nas, "nothing about us without us." "No taxation without representation" is, of course, an early U.S. version of the sentiment. "Nothing About Us Without Us" became known in the U.S. initially as a key theme of the disability rights movement. In fact, Nothing About Us Without Us was the title of two important books on disability rights published in 1998 (Charlton; Werner); both of which advocated for self-representation and control over the objectives of the disability rights movement.

The principle has been put to good use in a variety of other social movements, including by transgender activists and scholars. ${ }^{18}$ Sasha Constanza-Chock's Design Justice (2020) identifies "Nothing About Us Without Us" as a core commitment for design practices aimed at social change. The point is straightforward: Regulatory definitions can be thought of as tools we create to advance values and interests in specific institutional contexts. An important part of the pragmatic approach to definition I advocate is to consider such questions as who has the right to define and whose interests are served by competing definitions. Given the complexity of the issues described in the preceding chapters, the construction of regulatory definitions necessarily requires both trans and cis people to be at the table. ${ }^{19}$

The U.S. legal process - by which I include legislative and judicial actions-has and will continue to wrestle with these issues. I recognize that some supporters of full gender freedom will take a dim view of the sort of legal incrementalism this book describes (see, for example, Spade 2015), but I concur with Isaac West's argument that our best chance for social progress is not to withdraw from institutions of power and authority but to engage in "impure" politics, for "they are the only 
politics available for those who want to engage strangers in the quest for recognition and justice" $(2014,191)$. Writing in a similar key, Paisley Currah advocates efforts toward incremental reform as well as pursuing long-range efforts to deconstruct regulatory roles based on sex/gender classifications. ${ }^{20}$ In his words:

The short-term objective of recognition in order to alleviate the material problems of misclassified individuals in the here and now, and a long-term project that is necessarily less identitarian and more universalist, that looks at how sex classification figures into the reproduction of capital, race, and nation.

(in Fischel 2019, 95)

Though the Supreme Court majority decision in Bostock v. Clayton County in 2020 claimed to be using a conventional understanding of the word "sex" to decide that discrimination on the basis of sexual orientation or sexual identity violated Title VII's proscriptions against employment discrimination based on sex, it is almost certain that the question of defining "sex" is an issue the Court will need to reckon with again, and at greater depth (see Eskridge, Slocum, \& Th. Gries 2021). The historical situation facing the Court is, of course, symptomatic of the larger cultural pattern of needing to adapt our language use to evolving circumstances. As critical rhetoric scholar John Sloop notes, referencing Judith Butler, we find ourselves as part of a long struggle "in which our commonsense understandings about gender, sex, and sexuality are disarticulated and rearticulated in more contingent arrangements - arrangements that help increase those "possibilities for a livable life' for everyone" $(2004,148)$. Consistent with the sort of pragmatic ironist approach to language advocated here, Sloop concludes: "Literalization and deliteralization, freedom and constraint, each must, in different ways and in different critical moments, continue to be a part of the overall critical project" (149).

As the famed philosopher W. V. O. Quine noted, "Our patterns of thought or language have been evolving, under pressure of inherent inadequacies and changing needs, since the dawn of language; and, whether we help guide it or not, we may confidently look forward to more of the same" $(1969,24)$. The Transgender Exigency is just such a moment when our changing needs require an evolution of our patterns of thought and language. Beginning at an ironist/reformist stage of analysis with something like the tiered scrutiny I have advocated strikes me as a prudent step toward that evolution.

\section{Notes}

1 Quoted in McCreide (2012, 127).

2 McCloskey $(2019,277)$.

3 Hayton (2018). Hayton is a controversial figure and was criticized for wearing a t-shirt that said "Trans Women Are Men. Get over it!" (Hellen 2019). My inclusion of her quotation is not an endorsement of her views, but simply an effort to illustrate the range of transgender voices addressing the issues discussed in this book. 
4 Taylor (2021).

5 In the process of describing the "instability of definitions of who is truly human," Bourke notes that "the human" is "most commonly marked as male" (Bourke 2011, 13-14). Androcentrism has a long, long history that, combined with biological essentialism and gender polarization, has defined women's place as subordinate to men's (Bem 1994). See also Grimshaw (1986, 104-138).

6 GRC is defined as "a psychological state in which socialized gender roles have negative consequences for oneself or others" (O'Neil 2015, 10). An example of a harm to oneself would be the socialized resistance to asking for help or care when one needs it; an example of harm to others is when masculine socialization includes anti-gay beliefs and attitudes.

7 Multiple studies affirm that both men's and women's endorsement of traditional (or "hegemonic") masculinity was a strong predictor of support for Donald Trump for president both in the 2016 and 2020 elections (Vescio \& Schermerhorn 2021).

8 Brubaker (2016) notes that analogical reasoning in the case of transracial and transgender issues has been criticized, but I agree with him that race and gender are "systems of social classification with distinctive yet in some ways converging logics that can fruitfully be compared" (11).

9 I use the construction trans-r because the term "transracial" has been used primarily by those in the adoption community to refer to describe parents who adopt a child of a different race. As Kevin H. Vollmers, Executive Director of Gazillion Strong, notes: "Many members of the White press have appropriated and co-opted a deeply meaningful, historical term - transracial-from the adoptee community" (Wang 2015).

10 For a modest sampling of the discussion Tuvel's article sparked, see Botts (2018), Gordon (2018), Mc Manus (2019), Russell (2019), Sealey (2018), and Tuvel's response to her critics (2018). For an update on her position, see Tuvel (2021).

11 Not all scientists agree that race is a fiction, and some argue for the continued utility of racial categories. See Morning (2011, 2014), Torres (2020), and Yudell (2014).

12 Joshua Glascow, Sally Haslanger, Chike Jeffers, and Quayshawn Spencer collaborated to produce the book What is Race? Four Philosophical Views (2019). The authors nicely illustrate the point that one cannot ask "what is $\mathrm{x}$ ?" questions in a vacuum. The question of "what is race?" is coherent only once there is at least some agreement as to what the purpose of definition is, what interests are being served, and who should have the right to define. Not surprisingly, the book includes passages devoted to the Dolezal case.

13 Kenneth Prewitt argues that the U.S. Census should eventually phase out questions on race and ethnicity, but acknowledges that there is political utility for racial categories for certain public policies, despite their flaws, and that "color-blind arguments" sometimes are deployed "to buttress a conservative challenge to race-sensitive social justice policies (2013, 143).

14 See also the guide to inclusion by Chaudhry (2018).

15 Callie H. Burt offers a "feminist examination of definitional changes and sociolegal ramifications" of the current wording of the Equality Act and offers seven recommendations, including the suggestion that "we maintain the legal distinction between sex and gender" (2020). Several fellow sociologists wrote critical responses, to which Burt replied (2021). It is beyond the scope of this book to try to sort through the debate, though it should be obvious by this point that I believe there are some contexts in which self-identification without even a minimal durational requirement is problematic.

16 Coleman describes a similar approach that is "is based in well-established antidiscrimination law and requires attention to inherent biological differences, institutional mission, and the closeness of the means-ends nexus" $(2017,125)$. Her primary focus is on sex classification in sports, but as she notes, it could be applied to other contexts where segregation by sex is "mission critical."

17 Interestingly, the Massachusetts Supreme Judicial Court in Goodridge v. Department of Public Health (798 N.E.2d 941[Mass. 2003]) ruled that precluding same-sex marriage 
violated the Massachusetts constitution and that none of the reasons for forbidding same-sex marriage could survive even the low bar of the rational basis test (Schiappa 2012b).

18 See, for example, Lindberg (2017), Lynn (2017), and Scheim et al. (2019). The principle is sometimes extended to apply to scholarly writing concerning transgender people, which is why I have done my best to consult with trans scholars and friends throughout the writing of this book. If it is the case that there is no longer a one size fits all definition of sex/gender as this book has argued, then to be truly "about us all" it would benefit both cis and trans scholars to work arm in arm.

19 As Costanza-Chock puts it, "Analysis of political power in the design process-who sits at the table, who holds power over the project, what decision-making process is usedwill be fundamental to the successful future articulation of design justice in theory and practice" $(2020,107)$.

20 Currah's position is worth quoting at length: "As an activist, I have no problem using the language of rights and recognition in particular contexts. I pulled up every old saw about belonging and popular sovereignty in meetings with legislators. I have sat on agency advisory committees and worked with officials to change standards for sex reclassification, relying heavily on a medical model in the process (although a model that uses the authority of medical knowledges to argue against requiring body modification for sex reclassification). As a political theorist, I have suggested that the goal of recognition leaves intact the power of state actors to decide who gets what, and that ending the ability to use sex to distribute resources, rights, and privilege should be a priority for the movement. I have labored to understand, at the most mundane and micro levels of governmentality, what sex is doing and how that doing is imbricated with other systems of social stratification. I hold both positions simultaneously and don't see them as incommensurate" (in Fischel 2019, 95). 